\title{
BMJ Open Reoperation after breast-conserving surgery for cancer in Australia: statewide cohort study of linked hospital data
}

\author{
Marina T van Leeuwen, ${ }^{1}$ Michael O Falster, ${ }^{1}$ Claire M Vajdic, ${ }^{1}$ Philip J Crowe, ${ }^{2}$ \\ Sanja Lujic, ${ }^{1}$ Elizabeth Klaes, ${ }^{3}$ Louisa Jorm, ${ }^{1}$ Art Sedrakyan ${ }^{4}$
}

To cite: van Leeuwen MT, Falster MO, Vajdic CM, et al. Reoperation after breast-conserving surgery for cancer in Australia: statewide cohort study of linked hospital data. BMJ Open 2018;8:e020858. doi:10.1136/ bmjopen-2017-020858

- Prepublication history and additional material for this paper are available online. To view these files, please visit the journal online (http://dx.doi. org/10.1136/bmjopen-2017020858).

Received 29 November 2017 Revised 29 January 2018 Accepted 5 March 2018
Check for updates

${ }^{1}$ Centre for Big Data Research in Health, University of New

South Wales, Sydney, New South Wales, Australia

${ }^{2}$ Prince of Wales Clinical School, University of New South Wales, Sydney, New South Wales, Australia

${ }^{3}$ Breast Cancer Network Australia, Camberwell, Victoria, Australia

${ }^{4}$ Department of Healthcare Policy and Research, Weill Cornell Medical College, New York City, New York, USA

Correspondence to

Dr Marina T van Leeuwen;

m.vanleeuwen@unsw.edu.au

\section{ABSTRACT}

Objectives To investigate between-hospital variation in the probability of reoperation within 90 days of initial breast-conserving surgery (BCS), and the contribution of health system-level and other factors.

Design Population-based, retrospective cohort study.

Setting New South Wales (NSW), Australia.

Participants Linked administrative hospitalisation data were used to define a cohort of adult women undergoing initial BCS for breast cancer in NSW between 1 July 2002 and 31 December 2013.

Primary outcome measures Multilevel, crossclassified models with patients clustered within hospitals and residential areas were used to examine factors associated with any reoperation, and either re-excision or mastectomy, within 90 days.

Results Of 34458 women undergoing BCS, $29.1 \%$ underwent reoperation within 90 days, half of which were mastectomies. Overall, the probability of reoperation decreased slightly over time. However, there were divergent patterns by reoperation type; the probability of re-excision increased alongside a concomitant decrease in the probability of mastectomy. Significant betweenhospital variation was observed. Non-metropolitan location and surgery at low-volume hospitals were associated with a higher overall probability of reoperation, and of mastectomy specifically, after accounting for patientlevel factors, calendar year and area-level socioeconomic status. The magnitude of association with geographical location and surgical volume decreased over time. Conclusions Reoperation rates within 90 days of BCS varied significantly between hospitals. For women undergoing mastectomy after BCS, this represents a dramatic change in clinical course. Multilevel modelling suggests unwarranted clinical variation may be an issue, likely due to disparities in access to multidisciplinary breast cancer care and preoperative diagnostic procedures. However, the observed reduction in disparities over time is encouraging and indicates that guidelines and policy initiatives have the potential to improve regional breast cancer care.

\section{INTRODUCTION}

Clinical practice guidelines recommend that, where appropriate, women with early-stage
Strengths and limitations of this study

- The primary strength of this study is the use of best-practice multilevel modelling to investigate health system-level factors associated with reoperation after breast-conserving surgery.

- One limitation is the lack of detailed information on tumour characteristics known to contribute to margin status.

- Another limitation is the inability to incorporate patient or surgeon perspectives which may have influenced surgical decisions.

breast cancer be offered either breast-conserving surgery (BCS) with radiotherapy or mastectomy. ${ }^{12}$ Survival following BCS and radiotherapy is comparable to that following mastectomy. $^{3}$ However, BCS is associated with fewer postoperative complications ${ }^{4}$ and improved quality of life. ${ }^{5}$ In Australia, between $60 \%$ and $80 \%$ of women with earlystage breast cancer choose $\mathrm{BCS},{ }^{6-8}$ with similar figures reported in the USA. ${ }^{9}$

However, a number of women who undergo BCS require reoperation, either re-excision or completion mastectomy. ${ }^{10} 11$ This causes pain, suffering and anxiety, and may result in poorer cosmetic outcomes ${ }^{12}$ and higher rates of recurrence due to delays in commencing adjuvant therapy. ${ }^{13}$ The financial costs of reoperation are also considerable. ${ }^{14}$ Population-based studies in the USA ${ }^{10}$ and England ${ }^{11}$ estimate the rate of reoperation ranges between $20 \%$ and $30 \%$, though recent data suggest a downtrend in rates following the dissemination of clinical guidelines regarding surgical margins. ${ }^{15}$ Previous Australian data are limited; a rate of $30 \%$ was estimated based on linked registry from Western Australia, 1998-2000. ${ }^{8}$

Factors associated with reoperation can be broadly divided into patient-level 
sociodemographic and clinical factors, together with health system-level factors. ${ }^{16}$ Comprehensive investigation into health system factors, which are potentially modifiable, is lacking, with few large population-based studies conducted, ${ }^{8101117}$ only one of which ${ }^{10}$ used best-practice multilevel modelling techniques to capture health systemlevel variation. If confirmed, variation in reoperation rates related to health system, rather than patient-level factors, has important policy and practice implications. We present multilevel, cross-classified models examining patient-level, area-level contextual and health systemlevel factors associated with reoperation following BCS for breast cancer in a statewide, population-based cohort of women from New South Wales (NSW), Australia, 2002-2013.

\section{METHODS}

\section{Data sources and study population}

The NSW Admitted Patient Data Collection (APDC) records inpatient separations from all hospitals in NSW. Patient demographics, together with principal and secondary diagnoses and procedures are recorded for each separation. Diagnoses are coded according to the International Statistical Classification of Diseases and Related Problems, 10th Revision, Australian Modification (ICD-10-AM) and procedures according to the Australian Classification of Health Interventions (ACHI). The NSW Registry of Births, Deaths and Marriages (RBDM) records all deaths registered in NSW. An extract of the NSW APDC containing records between 1 July 2001 and 31 March 2014 was linked with the NSW RBDM by the NSW Centre for Health Record Linkage (http://www. cherel.org.au/) using an established probabilistic linkage method.

These data were used to define a cohort of adult $(\geq 16$ years) women with a diagnosis of invasive (ICD-10-AM C50) or in situ (ICD-10-AM D05) breast cancer who underwent initial BCS in NSW hospitals between 1 July 2001 and 31 March 2014, based on either principal or secondary diagnosis and procedure codes $(n=39255)$. We excluded women whose initial BCS occurred prior to 1 July $2002(\mathrm{n}=3070)$; this ensured a look back period of at least 12 months in which to assess record of previous breast or other cancer and comorbidities. Similarly, we excluded women with less than 90 days follow-up after their initial BCS $(n=896)$, either because it occurred after 31 December 2013, or they died within 90 days. We also excluded women who were not permanent residents of NSW ( $n=831)$. This left a final analytical cohort of $\mathrm{n}=34458$ women (figure 1 ).

BCS was defined by ACHI procedure codes for excision of lesion of breast (includes excisional biopsy), local excision of lesion of breast, segmental resection of breast and partial mastectomy (see online supplementary resource 1 for codes). Breast reoperation was defined by procedure codes for re-excision or mastectomy within 90 days of initial BCS. A period of 90 days was applied to avoid
Adult ( $\geq 16$ years) women with breast cancer undergoing BCS between 1 July 2001 - 31 March 2014, NSW, Australia (n=39,255)

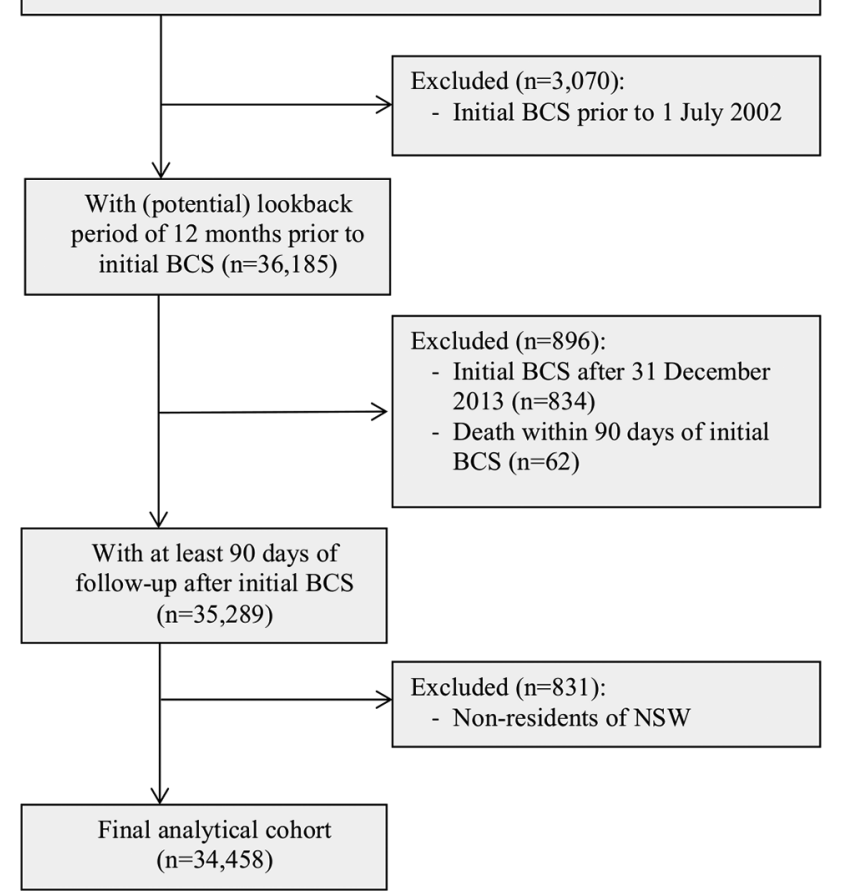

Figure 1 Flow diagram showing study inclusion and exclusion criteria. BCS, breast-conserving surgery; NSW, New South Wales.

including reoperations for local recurrence. Open (incisional) biopsy (30344-00, 31500-01) was not considered BCS. In women undergoing both re-excision and mastectomy following BCS, mastectomy was taken as the definitive procedure.

\section{Explanatory variables}

Patient-level sociodemographic variables at initial BCS included: age group, Australian Aboriginal or Torres Strait Islander status (hereafter referred to as 'Aboriginal') and country of birth. Patient-level clinical variables included: invasive or in situ tumour type; previous breast cancer recorded up to 12 months prior to initial BCS; and other previous cancer and comorbidities (defined as per Charlson Comorbidity Index ${ }^{18}$ ), recorded either at admission for initial BCS or up to 12 months prior. Previous breast cancer was assigned only where it could be determined that the record was not related to the diagnosis of, or neoadjuvant treatment for, the current breast tumour. Calendar year of initial BCS was also included.

Patient-level socioeconomic status is not recorded on the APDC; however, the Index of Relative Socioeconomic Disadvantage (quintiles) was included as an arealevel contextual variable, based on statistical local area (SLA) of residence defined using boundaries from the 2006 Australian Census. ${ }^{19}$ SLAs are one of the smallest geographical units available in the Australian Standard Geographical Classification, with 199 across the status of NSW (average population 32859 , range 346-133837). ${ }^{20}$ 
Health system-level variables at initial BCS included hospital identifier, public or private hospital type and BCS surgical volume $(<15,15-49,50+)$, based on the average annual number of BCS cases. Categorisation of BCS surgical volume was informed by visual inspection of its distribution (not shown). Geographical remoteness (metropolitan, non-metropolitan) was defined according to the Accessibility/Remoteness Index of Australia $^{20}$ and categorised as the combination of residential and hospital location, in order to capture differences in access to specialist, multidisciplinary inpatient with breast cancer care, as well as outpatient services, such as mammographical screening and preoperative diagnosis. While the majority $(95.3 \%)$ of women living in metropolitan areas underwent initial BCS in metropolitan hospitals, only $72.1 \%$ of women living in non-metropolitan areas were treated in non-metropolitan hospitals (data not shown elsewhere). Note, we did not consider hospital transfers between the hospital in which the initial BCS was conducted and that of the reoperation; factors related to the initial BCS were our primary interest.

\section{Statistical analysis}

Multilevel, cross-classified logistic regression models were used to examine the probability of reoperation versus no reoperation (binomial) and re-excision or mastectomy versus no reoperation (multinomial) within 90 days of initial BCS; supplementary binomial modelling examining the probability of mastectomy versus re-excision was also performed. Individuals were treated as the unit of analysis and were clustered according to both the hospital in which their initial BCS was performed and their SLA of residence, using cross-classified random intercept parameters. Variation in the probability of reoperation between hospitals and between SLAs was quantified using the variance of the random intercept parameters. ${ }^{21}$

Baseline models included the random intercepts for hospital and SLA, and age group at initial BCS, with subsequent models sequentially adding other patientlevel sociodemographic and clinical variables, calendar year, area-level contextual and health system-level variables. Adjusted ORs were obtained by exponentiating the regression parameters. Population averaged, predicted probabilities of reoperation (expressed as a percentage) were also estimated from the fitted model. We examined whether the association between health system-level factors and the probability of reoperation varied over time by separately including interaction terms between geographical location, BCS surgical volume and calendar (as a continuous variable) year of initial BCS in the corresponding main effect model.

All data preparation was performed in SAS V.9.4 and all modelling in MLwiN V.2.35. For all statistics, $p$ values were two tailed, and alpha was set at 0.05 . Models were fitted using Markov Chain Monte Carlo estimation with inference based on 20000 samples following a burn-in of 5000. Trajectories of stored parameter estimates were visually checked for irregular distributions and convergence to a unimodal distribution.

\section{RESULTS}

\section{Cohort characteristics}

Between 1 July 2002 and 31 December 2013, 34458 women with breast cancer underwent initial BCS in 161 NSW hospitals. The median age at initial BCS was 59 years (IQR 50-67 years). The majority (68.9\%) of women were born in Australia/New Zealand, and $0.9 \%$ identified as Aboriginal (table 1). Most women had invasive tumours, with $26.6 \%$ having in situ tumours or tumours with an in situ component; of these tumours, $\mathrm{n}=6377(69.6 \%)$ were ductal carcinoma in situ (DCIS; data not shown elsewhere). A small proportion $(0.7 \%)$ of women had previous breast cancer, $0.8 \%$ had another cancer and $8.0 \%$ had comorbidities recorded in hospital admissions data at or within 12 months of initial BCS. Most women $(69.5 \%)$ both resided and underwent initial BCS in metropolitan areas. Over half $(55.0 \%)$ attended private hospitals and a similar figure attended high-volume hospitals ( $\geq 50$ BCS cases per year). Women undergoing BCS in non-metropolitan hospitals were significantly less likely to have attended a private or high-volume hospital (see online supplementary resource 2 for cross-tabulation).

As shown in table 2, 10018 (29.1\%) of women underwent at least one reoperation within 90 days of initial BCS, either re-excision $(\mathrm{n}=5146,14.9 \%)$ or mastectomy $(\mathrm{n}=4872,14.1 \%)$. Of women undergoing mastectomy, $15.8 \%$ had also undergone re-excision (see online supplementary resource 3 for flow diagram). The proportion of women undergoing reoperation decreased slightly over time, from $30.1 \%$ to $27.8 \%$. Divergent patterns were observed by reoperation type; the proportion of women undergoing re-excision increased over time, from $13.0 \%$ in $2002-2005$ to $15.9 \%$ in $2010-2013$, whereas the proportion of women undergoing completion mastectomy decreased from $17.2 \%$ to $11.9 \%$.

\section{Multilevel modelling}

The population-averaged predicted probability of reoperation was $28.5 \%$, with estimates of $14.6 \%$ and $13.4 \%$ for re-excision and mastectomy, respectively (table 2). Significant variation was observed between hospitals in the overall probability of reoperation, as well as for re-excision and mastectomy, in both baseline and adjusted models (see online supplementary resource 4 for variance). Significant variation was also observed between residential SLAs in the probability of re-excision and mastectomy, though this was notably smaller than the variation seen between hospitals.

A clear pattern emerged for some explanatory factors (table 2; online supplementary resources 5 and 6). The probability of reoperation, whether by re-excision or mastectomy, was consistently higher among women of East Asian origin and those with in situ tumours and was consistently lower for women with a previous breast 
Table 1 Patient-level, area-level contextual and health system-level characteristics of women undergoing BCS 2002-2013, New South Wales, Australia

\begin{tabular}{lc}
\hline Variable & $\mathbf{n ~ ( \% )}$ \\
\hline Total cohort & $34458(100.0)$ \\
\hline Age (years) & \\
$<35$ & $579(1.7)$ \\
$35-49$ & $7308(21.2)$ \\
$50-64$ & $15209(44.1)$ \\
$65-79$ & $9309(27.0)$ \\
$80+$ & $2053(6.0)$ \\
\hline
\end{tabular}

Aboriginal status

\begin{tabular}{|c|c|}
\hline Non-Aboriginal & 34161 (99.1) \\
\hline Aboriginal & $297(0.9)$ \\
\hline \multicolumn{2}{|l|}{ Country of birth } \\
\hline Australia/New Zealand & 23746 (68.9) \\
\hline Europe & $4863(14.1)$ \\
\hline East Asia & $2217(6.4)$ \\
\hline Other & 2808 (8.2) \\
\hline Unknown & $824(2.4)$ \\
\hline \multicolumn{2}{|l|}{ Tumour type } \\
\hline Invasive & $25291(73.4)$ \\
\hline In situ/in situ component & 9167 (26.6) \\
\hline \multicolumn{2}{|l|}{ Previous breast cancer* } \\
\hline No & 34211 (99.3) \\
\hline Yes & $247(0.7)$ \\
\hline \multicolumn{2}{|l|}{ Other previous cancer* } \\
\hline No & 34169 (99.2) \\
\hline Yes & $289(0.8)$ \\
\hline \multicolumn{2}{|l|}{ No of comorbidities* } \\
\hline No comorbidities & 31689 (92.0) \\
\hline 1 & $2303(6.7)$ \\
\hline 2 & $348(1.0)$ \\
\hline $3+$ & $118(0.3)$ \\
\hline \multicolumn{2}{|l|}{ Year of initial BCS } \\
\hline 2002-2005 & $9868(28.6)$ \\
\hline 2006-2009 & $11662(33.8)$ \\
\hline 2010-2013 & $12928(37.5)$ \\
\hline \multicolumn{2}{|c|}{ Index of Relative Socioeconomic Disadvantage† } \\
\hline Quintile 5 (least disadvantaged) & $12319(35.8)$ \\
\hline Quintile 4 & $7116(20.7)$ \\
\hline Quintile 3 & $6860(19.9)$ \\
\hline Quintile 2 & 4104 (11.9) \\
\hline Quintile 1 (most disadvantaged) & 4059 (11.8) \\
\hline \multicolumn{2}{|l|}{ Hospital type } \\
\hline Public & $15516(45.0)$ \\
\hline Private & $18942(55.0)$ \\
\hline
\end{tabular}

Continued

\begin{tabular}{lc}
\hline Table 1 Continued & \\
\hline Variable & $\mathbf{n}(\%)$ \\
\hline $\begin{array}{l}\text { BCS surgical volume } \\
\quad<15\end{array}$ & $3278(9.5)$ \\
\hline $15-49$ & $12224(35.5)$ \\
$50+$ & $18956(55.0)$ \\
\hline $\begin{array}{l}\text { Residential and hospital location } \\
\quad \text { Metropolitan } \times \text { metropolitan }\end{array}$ & $23957(69.5)$ \\
\hline $\begin{array}{l}\text { Metropolitan } \times \text { non-metropolitan } \\
\text { Non-metropolitan } \times \text { metropolitan }\end{array}$ & $1180(3.4)$ \\
\hline $\begin{array}{l}\text { Non-metropolitan } \times \text { non- } \\
\text { metropolitan }\end{array}$ & $6719(1.6)$ \\
\hline
\end{tabular}

*Recorded on or within 12 months prior to initial BCS.

†Index of Relative Socioeconomic Disadvantage for statistical local area of residence.

$\ddagger$ Average annual number of BCS cases per hospital, 2002-2013.

$\mathrm{BCS}$, breast-conserving surgery.

cancer. The probability of reoperation was consistently higher among younger women compared with women aged 50-64 (the target age group for mammographical screening in Australia) and lower among older women; women undergoing reoperation in these age groups were significantly more likely to undergo mastectomy than re-excision. There was no association between reoperation and other previous cancers, the number of comorbidities, area-level socioeconomic status, or public or private hospital type.

For other factors, there were notable differences in the pattern of reoperation by re-excision or mastectomy (table 2; figure 2; online supplementary resources 5 and 6). As per the descriptive analyses, there was a decrease in the overall probability of reoperation over time, however, divergent patterns were observed; the probability of re-excision increased alongside a concomitant decrease in that for mastectomy. Women attending lower-volume hospitals had a higher overall probability of reoperation compared with those attending higher-volume ( $\geq 15 \mathrm{BCS}$ cases per year) hospitals. Women living in non-metropolitan areas and who attended non-metropolitan hospitals had a higher overall probability of reoperation than those living in metropolitan areas and who attended metropolitan hospitals. Both these associations were seen for mastectomy, but not for re-excision. Significant interactions were observed between the effect of year of initial BCS and each of geographical location $(p<0.001)$ and volume $(p=0.008)$ on the probability of mastectomy, with the magnitude of the differences reducing over time (figure 3). There was no difference in the overall probability of reoperation by indigenous status, although Aboriginal women had a higher probability of mastectomy than non-Aboriginal women, based on small numbers. 
Table 2 Adjusted and unadjusted probabilities of any reoperation, and separately, of re-excision or mastectomy within 90 days of initial BCS, New South Wales, Australia 2002-2013*

\begin{tabular}{|c|c|c|c|c|c|c|}
\hline \multirow[b]{2}{*}{ Variable } & \multicolumn{2}{|c|}{ Any reoperation } & \multicolumn{2}{|c|}{ Reoperation (re-excision) } & \multicolumn{2}{|c|}{ Reoperation (mastectomy) } \\
\hline & $\mathrm{n}$ & $\begin{array}{l}\text { Adjusted \% } \\
\text { (unadjusted \%)* }\end{array}$ & $\mathbf{n}$ & $\begin{array}{l}\text { Adjusted \% } \\
\text { (unadjusted \%)* }\end{array}$ & $\mathbf{n}$ & $\begin{array}{l}\text { Adjusted \% } \\
\text { (unadjusted \%) }\end{array}$ \\
\hline Total cohort & 10018 & 28.5 (29.1) & 5146 & $14.6(14.9)$ & 4872 & $13.4(14.1)$ \\
\hline \multicolumn{7}{|l|}{ Age (years) } \\
\hline$<35$ & 186 & $32.6(32.1)$ & 79 & $13.3(13.6)$ & 107 & $18.8(18.5)$ \\
\hline $35-49$ & 2645 & $35.6(36.2)$ & 1290 & $17.1(17.7)$ & 1355 & $18.0(18.5)$ \\
\hline $50-64$ & 4410 & $28.4(29.0)$ & 2418 & $15.5(15.9)$ & 1992 & $12.5(13.1)$ \\
\hline $65-79$ & 2429 & $26.1(26.1)$ & 1225 & $13.2(13.2)$ & 1204 & $12.5(12.9)$ \\
\hline $80+$ & 348 & $17.2(17.0)$ & 134 & $6.7(6.5)$ & 214 & $10.1(10.4)$ \\
\hline \multicolumn{7}{|l|}{ Aboriginal status } \\
\hline Non-Aboriginal & 9925 & $28.5(29.1)$ & 5111 & $14.4(15.0)$ & 4814 & $13.3(14.1)$ \\
\hline Aboriginal & 93 & $31.2(31.3)$ & 35 & $12.1(11.8)$ & 58 & $18.1(19.5)$ \\
\hline \multicolumn{7}{|l|}{ Country of birth } \\
\hline Australia/New Zealand & 6864 & $28.0(28.9)$ & 3478 & $14.6(14.7)$ & 3386 & $13.4(14.3)$ \\
\hline Europe & 1335 & $28.4(27.5)$ & 692 & $14.4(14.2)$ & 643 & $13.9(13.2)$ \\
\hline East Asia & 776 & $32.1(35.0)$ & 406 & $15.8(18.3)$ & 370 & $16.3(16.7)$ \\
\hline Other & 800 & $28.2(28.5)$ & 444 & $14.8(15.8)$ & 356 & $13.3(12.7)$ \\
\hline Unknown & 243 & $26.8(29.5)$ & 126 & $14.0(15.3)$ & 117 & $13.0(14.2)$ \\
\hline \multicolumn{7}{|l|}{ Tumour type } \\
\hline Invasive & 6557 & $25.2(25.9)$ & 3404 & $13.2(13.5)$ & 3153 & $12.1(12.5)$ \\
\hline In situ/mixed & 3461 & $37.6(37.8)$ & 1742 & $19.1(19.0)$ & 1719 & $18.5(18.8)$ \\
\hline \multicolumn{7}{|l|}{ Previous breast cancer† } \\
\hline No & 9973 & $28.6(29.2)$ & 5125 & $14.5(15.0)$ & 4848 & $13.5(14.2)$ \\
\hline Yes & 45 & $18.5(18.2)$ & 21 & $8.9(8.5)$ & 24 & $9.2(9.7)$ \\
\hline \multicolumn{7}{|l|}{ Previous other cancert } \\
\hline No & 9951 & $28.4(29.1)$ & 5117 & $14.4(15.0)$ & 4834 & $13.3(14.2)$ \\
\hline Yes & 67 & 25.5 (23.2) & 29 & $11.4(10.0)$ & 38 & $13.4(13.2)$ \\
\hline \multicolumn{7}{|l|}{ No of comorbidities $†$} \\
\hline No comorbidities & 9357 & $28.4(29.5)$ & 4836 & $15.0(15.3)$ & 4521 & $13.8(14.3)$ \\
\hline 1 & 557 & $26.7(24.2)$ & 268 & $13.6(11.6)$ & 289 & $13.2(12.6)$ \\
\hline 2 & 84 & $28.7(24.1)$ & 33 & $12.5(9.5)$ & 51 & $16.2(14.7)$ \\
\hline $3+$ & 20 & $22.0(17.0)$ & 9 & $11.1(7.6)$ & 11 & $10.9(9.3)$ \\
\hline \multicolumn{7}{|l|}{ Year of initial BCS } \\
\hline 2002-2005 & 2974 & $29.4(30.1)$ & 1282 & $12.3(13.0)$ & 1692 & $16.0(17.2)$ \\
\hline 2006-2009 & 3445 & 29.4 (29.5) & 1805 & $15.0(15.5)$ & 1640 & $13.4(14.1)$ \\
\hline 2010-2013 & 3599 & $27.7(27.8)$ & 2059 & $15.3(15.9)$ & 1540 & $11.4(11.9)$ \\
\hline \multicolumn{7}{|c|}{$\begin{array}{l}\text { Index of Relative Socioeconomic } \\
\text { Disadvantage } \neq\end{array}$} \\
\hline $\begin{array}{l}\text { Quintile } 5 \text { (least } \\
\text { disadvantaged) }\end{array}$ & 3656 & $28.7(29.7)$ & 1955 & $14.4(15.9)$ & 1701 & 13.5 (13.8) \\
\hline Quintile 4 & 2065 & $29.2(29.0)$ & 1086 & $14.8(15.3)$ & 979 & 13.5 (13.8) \\
\hline Quintile 3 & 1957 & $28.2(28.5)$ & 942 & $13.7(13.7)$ & 1015 & $13.5(14.8)$ \\
\hline Quintile 2 & 1189 & $29.1(29.0)$ & 560 & $14.6(13.7)$ & 629 & $13.6(15.3)$ \\
\hline $\begin{array}{l}\text { Quintile } 1 \text { (most } \\
\text { disadvantaged) }\end{array}$ & 1151 & $29.4(28.4)$ & 603 & $15.3(14.9)$ & 548 & $13.2(13.5)$ \\
\hline
\end{tabular}


Table 2 Continued

\begin{tabular}{|c|c|c|c|c|c|c|}
\hline \multirow[b]{2}{*}{ Variable } & \multicolumn{2}{|c|}{ Any reoperation } & \multicolumn{2}{|c|}{ Reoperation (re-excision) } & \multicolumn{2}{|c|}{ Reoperation (mastectomy) } \\
\hline & $\mathbf{n}$ & $\begin{array}{l}\text { Adjusted \% } \\
\text { (unadjusted \%)* }\end{array}$ & $\mathbf{n}$ & $\begin{array}{l}\text { Adjusted \% } \\
\text { (unadjusted \%)* }\end{array}$ & $\mathbf{n}$ & $\begin{array}{l}\text { Adjusted \% } \\
\text { (unadjusted \%)* }\end{array}$ \\
\hline \multicolumn{7}{|l|}{ Hospital type } \\
\hline Public & 4185 & $27.6(27.0)$ & 2099 & $13.6(13.5)$ & 2086 & $13.4(13.4)$ \\
\hline Private & 5833 & $29.9(30.8)$ & 3047 & $15.6(16.1)$ & 2786 & $14.0(14.7)$ \\
\hline \multicolumn{7}{|l|}{ BCS surgical volume§ } \\
\hline$<15$ & 1109 & $32.1(33.8)$ & 475 & $14.8(14.5)$ & 634 & $16.8(19.3)$ \\
\hline $15-49$ & 3373 & $27.3(27.6)$ & 1652 & $14.0(13.5)$ & 1721 & $12.9(14.1)$ \\
\hline $50+$ & 5536 & $28.7(29.2)$ & 3019 & $14.7(15.9)$ & 2517 & $13.1(13.3)$ \\
\hline \multicolumn{7}{|l|}{ Residential and hospital location } \\
\hline Metropolitan $\times$ metropolitan & 6859 & $27.7(28.6)$ & 3705 & $14.7(15.5)$ & 3154 & $12.6(13.2)$ \\
\hline $\begin{array}{l}\text { Metropolitan } \times \text { non- } \\
\text { metropolitan }\end{array}$ & 425 & $31.6(36.0)$ & 236 & $17.6(20.0)$ & 189 & $13.7(16.0)$ \\
\hline $\begin{array}{l}\text { Non-metropolitan } \times \\
\text { metropolitan }\end{array}$ & 656 & $27.4(25.2)$ & 329 & $13.7(12.6)$ & 327 & $13.2(12.6)$ \\
\hline $\begin{array}{l}\text { Non-metropolitan } \times \text { non- } \\
\text { metropolitan }\end{array}$ & 2078 & $32.2(30.9)$ & 876 & $13.4(13.0)$ & 1202 & $17.4(17.9)$ \\
\hline
\end{tabular}

*Adjusted \% (predicted probability) obtained from multilevel, cross-classified binomial (any reoperation) and multinomial (re-excision, mastectomy) logistic regression models, adjusted for patient-level factors, calendar year, area-level contextual factors and health system-level factors.

†Recorded on or within 12 months prior to initial BCS.

†Index of Relative Socioeconomic Disadvantage for statistical local area of residence.

§Average annual number of BCS cases per hospital, 2002-2013.

BCS, breast-conserving surgery.

\section{DISCUSSION}

In this statewide, population-based study of women undergoing initial BCS for breast cancer in Australia during 2002-2013, 29.1\% underwent reoperation within 90 days, almost half undergoing mastectomy.
Significant between-hospital variation was observed. Overall, the probability of reoperation decreased slightly over time. However, there were divergent patterns by reoperation type; the probability of re-excision increased alongside a concomitant decrease in the

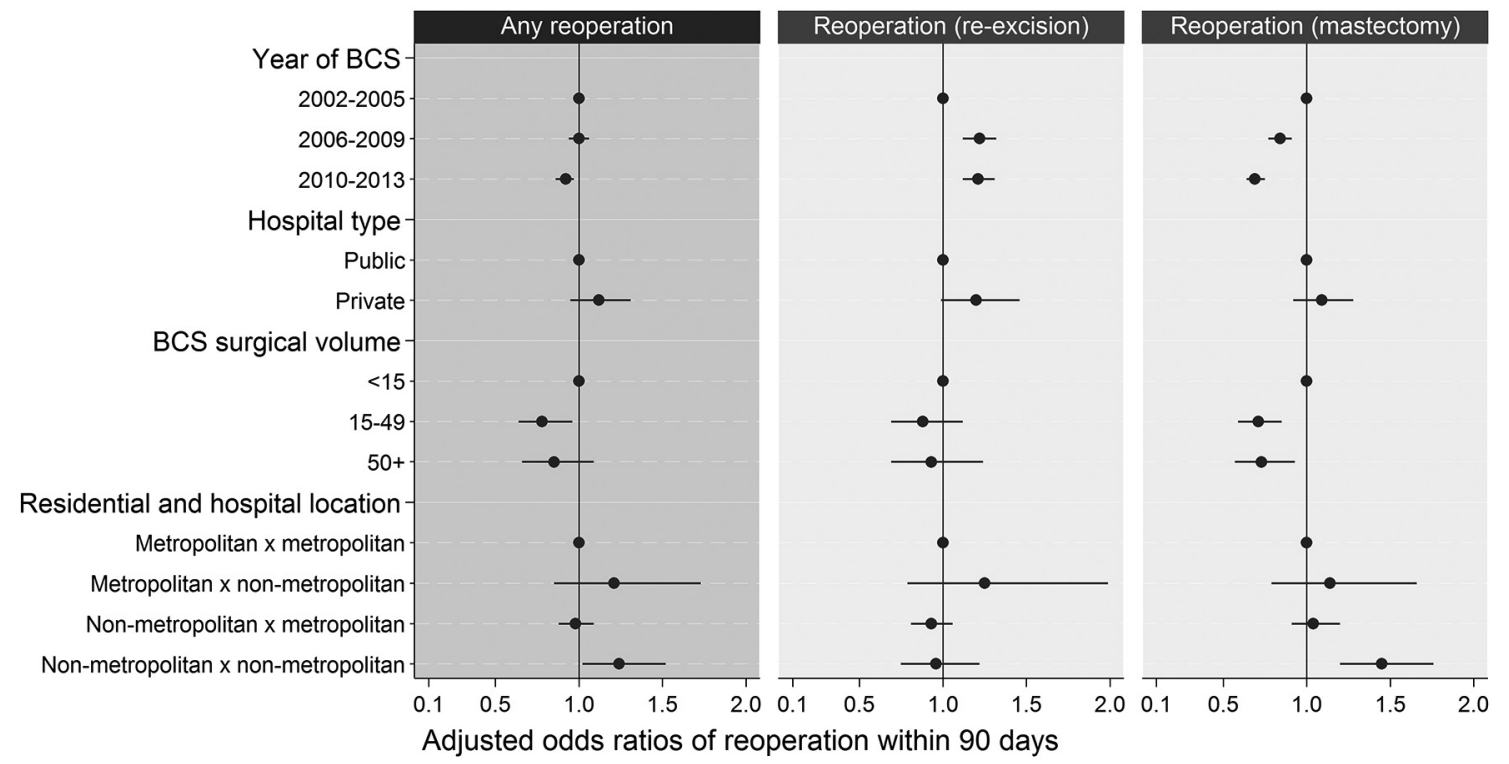

Figure 2 Adjusted ORs for any reoperation versus no reoperation, and separately, for re-excision or mastectomy versus no reoperation within 90 days of initial breast-conserving surgery (BCS), New South Wales, Australia, 2002-2013. Shows ORs for calendar year and health system-level factors fully adjusted for patient-level and area-level contextual factors based on multilevel, cross-classified binomial (any reoperation) and multinomial (re-excision, mastectomy) logistic regression models. 


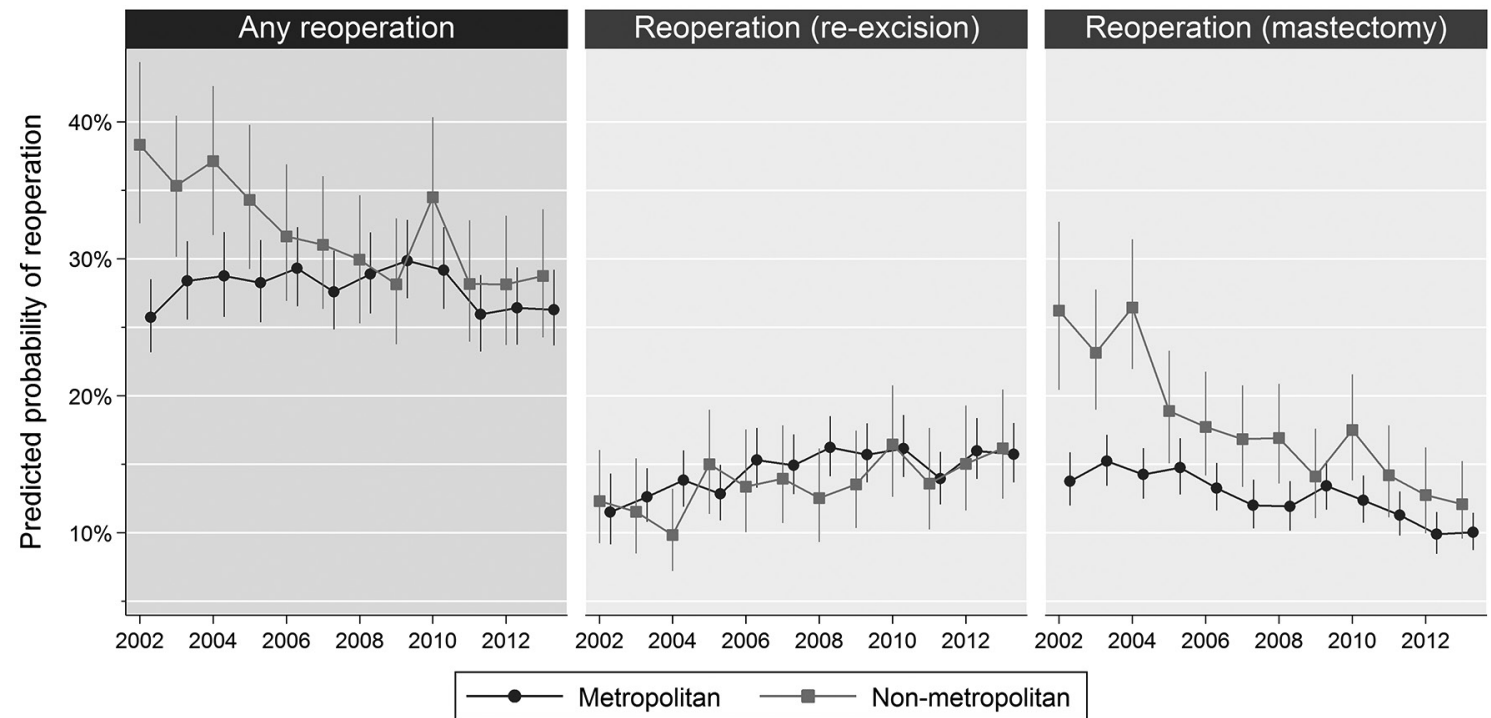

Figure 3 Population-averaged predicted probabilities of any reoperation, and separately, of re-excision or mastectomy, within 90 days of initial breast-conserving surgery, by calendar year and location, New South Wales, Australia, 2002-2013. Predicted probabilities obtained from fully adjusted multilevel, cross-classified binomial (any reoperation) and multinomial (re-excision, mastectomy) logistic regression models containing interaction terms between discrete calendar years geographical location. For illustrative purposes, graph restricted to concordant metropolitan or non-metropolitan residential and hospital location.

probability of mastectomy. Women living in non-metropolitan areas and who attended non-metropolitan hospitals, as well as those attending low-volume hospitals, had a higher probability of reoperation, particularly mastectomy, even after adjusting for patient-level and area-level contextual factors. The magnitude of association with geographical location and volume decreased over time.

This is the first study to have used multilevel modelling to thoroughly investigate the role of health system-level, area-level contextual and patient-level factors in reoperation following BCS. It is also the first to have applied multilevel multinomial modelling to separately examine factors associated with re-excision and mastectomy; this is important, as some associations were obscured when examined for all reoperations combined, in a demonstration of Simpson's paradox. ${ }^{22}$

This is one of few published population-based studies. NSW hospitalisation data have been demonstrated to have high sensitivity and specificity in identifying patients with breast cancer when validated against cancer registry $\mathrm{data}^{23}$ and to provide unbiased estimates of BCS. ${ }^{24}$ However, the potential for miscoding within administrative datasets is acknowledged. Further, due to inherent characteristics of ICD-10-AM diagnostic codes, it is not possible to distinguish excisional biopsies performed for diagnostic purposes from those performed with the intention of complete excision. ${ }^{8}$ We were unable to account for laterality. However, the availability in ICD-10-AM of a diagnostic code-specific for re-excision and the low likelihood of contralateral mastectomy within 90 days of BCS means that any misclassification of reoperation due to absence of data on laterality would be minimal. We could not consider margin status, nor fully account for stage, histology and other tumour characteristics known to contribute to margin status. However, it is unlikely that variation based on these factors would have accounted for the hospital variation we observed. Finally, we could not incorporate patient or surgeon perspectives; the complexities of decision-making in the surgical treatment of breast cancer cannot be adequately assessed using administrative data. ${ }^{8}$

Our observed overall reoperation rate is similar to that for contemporaneous, population-based cohorts in the USA (New York, 2002-2013; 31\%) ${ }^{10}$ and the Netherlands (Rotterdam, 2006-2007; 29\%) ${ }^{25}$ but higher than that from the UK (England, 2005-2008; 20\%).$^{11}$ Lower rates were reported from Spain (Catalonia, 2005-2011; 12\%) ${ }^{26}$ and Ireland $(2002-2008 ; 17 \%),{ }^{17}$ but these studies did not include DCIS.

Variability in reoperation rates can be partly explained by differences in approach to surgical margins. Reoperation primarily occurs due to positive or negative close margins. ${ }^{27}$ Historically, there has been lack of consensus on what constitutes an adequate negative margin, ${ }^{28} 29$ though in the context of multimodality breast cancer treatment, wider margins are no longer superior in terms of local recurrence. ${ }^{15}$ Consensus guidelines were recently published recommending 'no ink on tumour' as an adequate surgical margin for patients with early-stage invasive breast cancer undergoing BCS with radiotherapy $(2014)^{30}$ and $2 \mathrm{~mm}$ for DCIS (2016). ${ }^{31}$ This fundamental shift in approach is reflected in our observation of changing proportions of women undergoing re-excision and mastectomy over time, also noted in the New York cohort, ${ }^{10}$ and in recent analyses of US Surveillance, Epidemiology and End Results registry data. ${ }^{15}$ 
Between-hospital variation in reoperation rates has not been previously demonstrated using multilevel analyses. Variability in reoperation rates between surgeons was observed in the New York cohort, ${ }^{10}$ as well as in a multisite cohort of US patients with breast cancer, though this study was not population based. ${ }^{32}$ Surgical volume, an accepted surrogate for specialisation, is one possible explanation. ${ }^{10} 1725273233$ Specialist breast cancer surgeons may be more proficient at obtaining negative margins, and less likely to re-excise close margins. ${ }^{16}$ Patient selection and appropriateness of BCS as the initial treatment choice is also a factor. Anecdotal evidence suggests that treatment decisions made in high-volume hospitals are often made by multidisciplinary teams (MDTs) and differ from those made by clinicians working in isolation. ${ }^{34}$

Differences in the probability of reoperation, particularly mastectomy, between women living and undergoing treatment in metropolitan versus non-metropolitan areas potentially reflects differential access to specialist, multidisciplinary breast cancer care. A 2006 survey of Australian breast cancer surgeons showed, for example, that participation in MDTs is higher for surgeons in metropolitan than non-metropolitan areas. ${ }^{35}$ Differential access to specialised radiological services able to perform localisation of impalpable lesions and intraoperative assessment to confirm complete excision may also be a valid consideration, as is access to preoperative diagnostic services. ${ }^{8}$ Women in remote areas of Australia are less likely to have undergone preoperative diagnosis by fine-needle aspiration or core biopsy, and instead, more likely to have undergone surgical biopsy ${ }^{36}$; this may be exacerbated by lower rates of mammographical screening and referral for preoperative diagnosis. ${ }^{37}$ Increased risk of reoperation could be expected, therefore, as BCS may have been performed for diagnostic purposes rather than with the intention of complete excision. ${ }^{8}$ This was evidenced in US surgical ${ }^{32}$ and Medicare cohort data ${ }^{33}$ where lack of preoperative diagnosis was associated with higher rates of reoperation.

Health system-level factors were found to be significant independent of patient-level factors, such as younger age,,$^{1011172738}$ and in situ tumour type. ${ }^{101138}$ Positive margins are more frequently observed in younger women, as smaller volumes of breast tissue are resected and tumours tend to have adverse histological features. ${ }^{39} 40$ In addition, preoperative diagnosis in younger women may be complicated by greater breast density and lower mammographical sensitivity. ${ }^{40}$ Comparatively smaller breast size and greater breast density ${ }^{41}$ may similarly account for the high probability of reoperation seen in Asian women. ${ }^{38}$ Most $(70 \%)$ in situ tumours in our cohort were DCIS. The margins of DCIS are less well defined than for invasive tumours, and extension into the breast tissue can be difficult to determine. ${ }^{42}$ Hence, DCIS is more often associated with positive margins. ${ }^{43} 44$ The higher probability of mastectomy seen among Aboriginal women should be interpreted cautiously due to small numbers, but nevertheless suggests they may be a high-risk group, independent of their place of residence. Aboriginal women in Australia have lower rates of screening participation, ${ }^{37}{ }^{45}$ disparate access to $\mathrm{BCS}^{7}$ and lower survival after breast cancer surgery. ${ }^{45}$ Interestingly, we did not observe an association with area-level socioeconomic status, which has been related to differential access to $\mathrm{BCS}^{746}$ and survival, ${ }^{47}$ but not to differences in rates of screening. ${ }^{37}$

In summary, in a population-based cohort of Australian women, $29.1 \%$ underwent reoperation within 90 days of BCS, almost half undergoing mastectomy. For these women, this represents a dramatic change in clinical course. We used robust statistical methodology to show between-hospital variation in reoperation rates, and an association with health system-level factors, after considering patient-level and area-level contextual factors.

The association of low-BCS surgical volume and non-metropolitan location with mastectomy after BCS highlights the potential role of access to multidisciplinary, specialist breast cancer care in reducing unwarranted clinical variation. Other considerations should include: improving access to high-quality preoperative diagnostic imaging and biopsy, methods to localise non-palpable tumours, intraoperative margin assessment, and surgeon education in oncoplastic techniques and compliance with margin guidelines. This is not unique to the Australian setting; a consensus conference held among the American Society of Breast Cancer Surgeons in 2015 advocated several such evidence-based recommendations to reduce variability in reoperation rates. ${ }^{48}$ Disparities in the reoperation rate between metropolitan and non-metropolitan areas, and between low-volume and high-volume hospitals, appear to have reduced. This is encouraging and suggests that policy initiatives to improve regional breast cancer care in NSW over the past decade may have had some success. ${ }^{49} 50$

Acknowledgements We would like to acknowledge the NSW Ministry of Health and the NSW Register of Births, Deaths and Marriages for allowing access to the data, and the Centre for Health Record Linkage for conducting the probabilistic linkage of records.

Contributors All authors (MTVL, MOF, CMV, PJC, SL, EK, LJ and AS) made substantial contributions to the study concept and design. MTvL had full access to the study data. MTVL, CMV, MOF and SL were responsible for developing the analytical protocol, and MTVL and MOF for executing the statistical analyses. All authors (MTVL, MOF, CMV, PJC, SL, EK, LJ and AS) made substantial contributions to the interpretation of the data. MTVL, MOF and CMV drafted the manuscript; all authors (MTVL, MOF, CMV, PJC, SL, EK, LJ and AS) revised it critically for important intellectual content. All authors (MTVL, MOF, CMV, PJC, SL, EK, LJ and AS) have approved the final version of the manuscript.

Funding Data were provided by The Indigenous Health Outcomes Patient Evaluation (IHOPE) study, supported by a National Health and Medical Research Council Project Grant (no: 573113). MTvL is supported by a Postdoctoral Research Fellowship from the National Health and Medical Research Council (no: 1012141).

\section{Competing interests None declared.}

Patient consent Detail has been removed from this case description/these case descriptions to ensure anonymity. The editors and reviewers have seen the detailed information available and are satisfied that the information backs up the case the authors are making. 
Ethics approval Ethical approval was obtained from the NSW Population and Health Services Research Ethics Committee and the NSW Aboriginal Health and Medical Research Council Ethics Committee.

Provenance and peer review Not commissioned; externally peer reviewed.

Data sharing statement № additional data are available.

Open Access This is an Open Access article distributed in accordance with the Creative Commons Attribution Non Commercial (CC BY-NC 4.0) license, which permits others to distribute, remix, adapt, build upon this work non-commercially, and license their derivative works on different terms, provided the original work is properly cited and the use is non-commercial. See: http://creativecommons.org/ licenses/by-nc/4.0/

(c) Article author(s) (or their employer(s) unless otherwise stated in the text of the article) 2018. All rights reserved. No commercial use is permitted unless otherwise expressly granted.

\section{REFERENCES}

1. National Health and Medical Research Council. Clinical practice guidelines for the managment of early breast cancer. 2nd edition. Canberra: Commonwealth of Australia, 2001. (accessed 4 Apr 2017).

2. Senkus E, Kyriakides S, Ohno S, et al. Primary breast cancer: ESMO Clinical Practice Guidelines for diagnosis, treatment and follow-up. Ann Oncol 2015;26(Suppl 5):v8-v30.

3. Litière $\mathrm{S}$, Werutsky G, Fentiman IS, et al. Breast conserving therapy versus mastectomy for stage I-II breast cancer: 20 year followup of the EORTC 10801 phase 3 randomised trial. Lancet Oncol 2012;13:412-9.

4. Pyfer B, Chatterjee A, Chen L, et al. Early postoperative outcomes in breast conservation surgery versus simple mastectomy with implant reconstruction: a NSQIP analysis of 11,645 patients. Ann Surg Oncol 2016;23:92-8.

5. Engel J, Kerr J, Schlesinger-Raab A, et al. Quality of life following breast-conserving therapy or mastectomy: results of a 5-year prospective study. Breast J 2004;10:223-31.

6. Roder D, Zorbas H, Kollias J, et al. Factors predictive of treatment by Australian breast surgeons of invasive female breast cancer by mastectomy rather than breast conserving surgery. Asian Pac J Cancer Prev 2013;14:539-45.

7. Baade PD, Dasgupta P, Youl PH, et al. Geographical inequalities in surgical treatment for localized female breast cancer, Queensland, Australia 1997-2011: improvements over time but inequalities remain. Int J Environ Res Public Health 2016;13:729.

8. Spilsbury K, Semmens JB, Saunders CM, et al. Subsequent surgery after initial breast conserving surgery: a population based study. ANZ J Surg 2005;75:260-4.

9. Habermann EB, Abbott A, Parsons HM, et al. Are mastectomy rates really increasing in the United States? J Clin Oncol 2010;28:3437-41.

10. Isaacs AJ, Gemignani ML, Pusic A, et al. Association of breast conservation surgery for cancer with 90-day reoperation rates in New York State. JAMA Surg 2016;151:648-55.

11. Jeevan $\mathrm{R}$, Cromwell DA, Trivella $\mathrm{M}$, et al. Reoperation rates after breast conserving surgery for breast cancer among women in England: retrospective study of hospital episode statistics. BMJ 2012;345:e4505 https://dx.doi.org/.

12. Heil J, Breitkreuz K, Golatta M, et al. Do reexcisions impair aesthetic outcome in breast conservation surgery? Exploratory analysis of a prospective cohort study. Ann Surg Oncol 2012;19:541-7.

13. Menes TS, Tartter PI, Bleiweiss I, et al. The consequence of multiple re-excisions to obtain clear lumpectomy margins in breast cancer patients. Ann Surg Oncol 2005;12:881-5.

14. Pataky RE, Baliski CR. Reoperation costs in attempted breastconserving surgery: a decision analysis. Curr Oncol 2016;23:314-21.

15. Morrow M, Abrahamse P, Hofer TP, et al. Trends in Reoperation after initial lumpectomy for breast cancer: addressing overtreatment in surgical management. JAMA Oncol 2017;3:1352-1357.

16. Hughes L, Hamm J, McGahan C, et al. Surgeon volume, patient age, and tumor-related factors influence the need for re-excision after breast-conserving surgery. Ann Surg Oncol 2016;23:656-64.

17. de Camargo Cancela M, Comber H, Sharp L. Hospital and surgeon caseload are associated with risk of re-operation following breastconserving surgery. Breast Cancer Res Treat 2013;140:535-44.

18. Quan H, Sundararajan V, Halfon P, et al. Coding algorithms for defining comorbidities in ICD-9-CM and ICD-10 administrative data. Med Care 2005;43:1130-9.

19. Australian Bureau of Statistics. Census of Population and Housing: Socio-Economic Indexes for Areas (SEIFA), Australia 2006. Canberra:
Australian Bureau of Statistics, 2008. updated 10 July 2017. ABS Catalogue no. 2033.0.55.001. (accessed 10 Jul 2017).

20. Australian Bureau of Statistics. Statistical Geography Volume 1 Australian Standard Geographical Classification (ASGC). Canberra: Australian Bureau of Statistics, 2006. updated 10 July 2017. ABS Catalogue no. 1216.0 [Available. (accessed $10 \mathrm{Jul}$ 2017).

21. Merlo J, Yang M, Chaix B, et al. A brief conceptual tutorial on multilevel analysis in social epidemiology: investigating contextual phenomena in different groups of people. J Epidemiol Community Health 2005;59:729-36.

22. Blyth CR. On simpson's paradox and the sure-thing principle. J Am Stat Assoc 1972;67:364-6.

23. Kemp A, Preen DB, Saunders C, et al. Ascertaining invasive breast cancer cases; the validity of administrative and self-reported data sources in Australia. BMC Med Res Methodol 2013;13:17.

24. McGeechan K, Kricker A, Armstrong B, et al. Evaluation of linked cancer registry and hospital records of breast cancer. Aust $N Z \mathrm{~J}$ Public Health 1998;22:765-70.

25. Talsma AK, Reedijk AM, Damhuis RA, et al. Re-resection rates after breast-conserving surgery as a performance indicator: introduction of a case-mix model to allow comparison between Dutch hospitals. Eur J Surg Oncol 2011;37:357-63.

26. Escribà JM, Esteban L, Gálvez J, et al. Reoperations after primary breast conserving surgery in women with invasive breast cancer in Catalonia, Spain: a retrospective study. Clin Trans/ Oncol 2017; 19:448-56.

27. Landercasper J, Whitacre E, Degnim AC, et al. Reasons for reexcision after lumpectomy for breast cancer: insight from the American Society of Breast Surgeons Mastery(SM) database. Ann Surg Oncol 2014;21:3185-91.

28. Houssami N, Macaskill P, Marinovich ML, et al. The association of surgical margins and local recurrence in women with early-stage invasive breast cancer treated with breast-conserving therapy: a meta-analysis. Ann Surg Oncol 2014;21:717-30.

29. Marinovich ML, Azizi L, Macaskill P, et al. The association of surgical margins and local recurrence in women with ductal carcinoma in situ treated with breast-conserving therapy: a meta-analysis. Ann Surg Oncol 2016;23:3811-21.

30. Moran MS, Schnitt SJ, Giuliano AE, et al. Society of surgical oncology-american society for radiation oncology consensus guideline on margins for breast-conserving surgery with whole-breast irradiation in stages $\mathrm{i}$ and ii invasive breast cancer. J Clin Oncol 2014;32:1507-15.

31. Morrow M, Van Zee KJ, Solin LJ, et al. Society of surgical oncologyamerican society for radiation oncology-american society of clinical oncology consensus guideline on margins for breast-conserving surgery with whole-breast irradiation in ductal carcinoma in situ. $J$ Clin Oncol 2016;34:4040-6.

32. McCahill LE, Single RM, Aiello Bowles EJ, et al. Variability in reexcision following breast conservation surgery. JAMA 2012;307:467-75.

33. Eberth JM, Xu Y, Smith GL, et al. Surgeon influence on use of needle biopsy in patients with breast cancer: a national medicare study. $J$ Clin Oncol 2014;32:2206-16.

34. Chang $\mathrm{JH}$, Vines $\mathrm{E}$, Bertsch $\mathrm{H}$, et al. The impact of a multidisciplinary breast cancer center on recommendations for patient management: the University of Pennsylvania experience. Cancer 2001;91:1231-7

35. Marsh CJ, Boult M, Wang JX, et al. National Breast Cancer Audit: the use of multidisciplinary care teams by breast surgeons in Australia and New Zealand. Med J Aust 2008;188:385-8.

36. Azzopardi J, Walsh D, Chong C, et al. Impact of geographic location on surgical outcomes of women with breast cancer. ANZ J Surg 2014;84:735-9.

37. Australian Institute of Health and Welfare (AIHW) and Cancer Australia. Breast Cancer in Australia: An Overview. Canberra: AlHW, 2012. Cancer series no. 71. Cat. no. CAN 67. (accessed 7 Jun 2017).

38. Wilke LG, Czechura T, Wang C, et al. Repeat surgery after breast conservation for the treatment of stage 0 to II breast carcinoma: a report from the National Cancer Data Base, 2004-2010. JAMA Surg 2014;149:1296-305.

39. Vrieling $C$, Collette $L$, Fourquet $A$, et al. Can patient-, treatment- and pathology-related characteristics explain the high local recurrence rate following breast-conserving therapy in young patients? Eur $J$ Cancer 2003;39:932-44.

40. Wang J, Kollias J, Boult M, et al. Patterns of surgical treatment for women with breast cancer in relation to age. Breast $J$ 2010;16:60-5.

41. Rajaram N, Mariapun S, Eriksson M, et al. Differences in mammographic density between Asian and Caucasian 
populations: a comparative analysis. Breast Cancer Res Treat 2017; 161:353-62.

42. Skinner KA, Silberman $H$, Sposto $R$, et al. Palpable breast cancers are inherently different from nonpalpable breast cancers. Ann Surg Oncol 2001;8:705-10.

43. Langhans $L$, Jensen MB, Talman MM, et al. Reoperation rates in ductal carcinoma in situ vs invasive breast cancer after wire-guided breast-conserving surgery. JAMA Surg 2017;152:378-84.

44. van Deurzen CH. Predictors of surgical margin following breastconserving surgery: a large population-based cohort study. Ann Surg Oncol 2016;23:627-33.

45. Roder D, Webster F, Zorbas $\mathrm{H}$, et al. Breast screening and breast cancer survival in Aboriginal and Torres Strait Islander women of Australia. Asian Pac J Cancer Prev 2012;13:147-55.
46. Azzopardi J, Walsh D, Chong C, et al. Surgical treatment for women with breast cancer in relation to socioeconomic and insurance status. Breast J 2014;20:3-8.

47. Dasgupta P, Youl PH, Pyke C, et al. Geographical disparity in breast reconstruction following mastectomy has reduced over time. ANZ J Surg 2017;87:E183-7.

48. Landercasper J, Attai D, Atisha D, et al. Toolbox to reduce lumpectomy reoperations and improve cosmetic outcome in breast cancer patients: the american society of breast surgeons consensus conference. Ann Surg Oncol 2015;22:3174-83.

49. Murphy C, Sabesan S, Steer C, et al. Oncology service initiatives and research in regional Australia. Aust J Rural Health 2015;23:40-8.

50. Fox P, Boyce A. Cancer health inequality persists in regional and remote Australia. Med J Aust 2014;201:445-6. 